\title{
PENGARUH IRADIASI SINAR GAMMA COBALT - 60 TERHADAP PERTUMBUHAN DAN HASIL TANAMAN MENTIMUN (Cucumis sativus L.) LOKAL MADURA
}

\author{
The Effect of Cobalt - 60 Gamma Iradiation on the Growth and Production of Local Madura \\ Cucumber (Cucumis sativus L.) \\ Vega Melania Fitra ${ }^{1 *}$ Guniarti $^{2}$ dan Ida Retno Moeljani $^{3}$ \\ ${ }^{1,2,3)}$ Program Studi Agroteknologi, Fakultas Pertanian, Universitas Pembangunan \\ Nasional "Veteran" Jawa Timur \\ ${ }^{1 *}$ vegafitra11@gmail.com
}

\begin{abstract}
ABSTRAK
Mentimun lokal madura ini memiliki keunggulan yaitu bentuk yang besar dan rasa yang gurih. Benih timun lokal Madura ini mempunyai ciri khusus dibandingkan dengan mentimun Jawa yaitu mengandung air yang cukup banyak dan biji yang sangat banyak. Petani di Indonesia banyak menanam varietas mentimun introduksi karena memiliki buah yang lebih besar dan seragam, akan tetapi benih ini tidak dapat ditanam kembali pada periode tanam berikutnya. Oleh karena itu perlu dilakukan upaya khusus untuk memperbaiki sifat genetik benih pada tanaman mentimun melalui pemuliaan tanaman. Penelitian ini bertujuan untuk untuk mengetahui dan mendapatkan nilai $\mathrm{LD}_{50}$ serta mengetahui dan mendapatkan hasil pertumbuhan dari tanaman mentimun lokal Madura yang di iradiasi sinar Gamma Cobalt-60. Penelitian ini dilaksanakan di Desa Burneh, Kecamatan Burneh, Kabupaten Bangkalan. Waktu pelaksanaan penelitian dimulai pada bulan Mei 2021 sampai bulan Juni 2021. Terdiri dari 11 taraf dengan kode $\mathrm{D}_{0}$ tanpa iradiasi (0Gy/ kontrol), $\mathrm{D}_{1}$ (100Gy), $\mathrm{D}_{2}$ (200Gy), $\mathrm{D}_{3}$ (300Gy), $\mathrm{D}_{4}$ (400Gy), $\mathrm{D}_{5}$ (500Gy), $\mathrm{D}_{6}$ (600Gy), $\mathrm{D}_{7}$ (700Gy), $\mathrm{D}_{8}(800 \mathrm{~Gy}), \mathrm{D}_{9}(900 \mathrm{~Gy}), \mathrm{D}_{10}$ (1000Gy). Terdapat 11 petak percobaan dan menggunakan single plant yang merupakan menaman tanpa adanya ulangan di lingkungan pertanaman yang sama dengan analisis uji t taraf 5\% dan 1\%. Hasil penelitian menunjukan dosis iradiasi sinar gamma Cobalt-60 mendapatkan nilai Lethal Dose 20 (LD20) sebesar 306,752 Gy dan Lethal Dose 50 (LD50) sebesar 690,92 Gy. Iradiasi sinar gamma Cobalt60 berpengaruh terhadap pertumbuhan dan hasil produksi pada parameter tinggi tanaman, bobot buah dan panjang buah pada mentimun lokal Madura.
\end{abstract}

\section{Kata kunci : Iradiasi Sinar Gamma Cobalt-60, Lethal Dose, Mentimun}

\section{ABSTRACT}

This Madura local cucumber has the advantage of having a large shape and savory taste. These local Madura cucumber seeds have special characteristics compared to Javanese cucumbers, namely they contain a lot of water and a lot of seeds. Farmers in Indonesia plant a lot of introduced cucumber varieties because they have larger and uniform fruits, but these seeds cannot be planted again in the next planting period. Therefore, it is necessary to make special efforts to improve the genetic characteristics of seeds in cucumber plants through plant breeding. This study aims to determine and obtain the LD50 value and to determine and obtain the growth yield of local Madura cucumber plants irradiated by Gamma Cobalt-60 rays. This research was conducted in Burneh Village, Burneh District, Bangkalan Regency. The time of the research starts from May 2021 to June 2021. Consists of 11 levels with codes D0 without irradiation (OGy/control), D1 (100Gy), D2 (200Gy), D3 (300Gy), D4 (400Gy), D5 ( 500Gy), D6 (600Gy), D7 (700Gy), D8 (800Gy), D9 (900Gy), D10 (1000Gy). There are 11 experimental plots and using a single plant which is a plant without replication in the same planting environment with T-test analysis at $5 \%$ and $1 \%$ levels. The results showed that the Cobalt-60 gamma ray irradiation dose obtained a Lethal Dose 20 (LD20) of 306.752 Gy and a Lethal Dose of 50 (LD50) of 690.92 Gy. Cobalt-60 gamma ray irradiation affects the growth and yield of plant height, fruit weight and fruit length parameters on Madura local cucumbers.

Keywords: Cobalt-60 Gamma Radiation, Lethal Dose, Cucumber 
Perbal: Jurnal Pertanian Berkelanjutan

Fakultas Pertanian Universitas Cokroaminoto Palopo

\section{PENDAHULUAN}

Tanaman mentimun (Cucumis sativus

L.) termasuk dalam jenis tanaman sayuran dari famili Cucurbitaceae yang merambat. Mentimun menjadi tulang punggung masyarakat Madura khususnya di Kabupaten Bangkalan. Petani lokal Madura ini menghasilkan benih mentimun sendiri, sehingga bisa dikonsumsi kembali. Umur mentimun ini sekitar 1 sampai dengan 2 bulan. Keunggulan dari benih ini memiliki bentuk yang besar dan rasa yang gurih. Benih timun lokal Madura ini mempunyai ciri khusus dibandingkan dengan mentimun Jawa yaitu mengandung air yang cukup banyak dan biji yang sangat banyak. Indriani et al. (2008) mengungkapkan bahwa dengan adanya keragaman genetik, maka sifat yang diinginkan untuk memperoleh varietas unggul baru akan tercapai.

Berdasarkan data Badan Pusat Statistik (2015) produksi mentimun pada tahun 2009-2015 mengalami penurunan dari 10.39 ton $\mathrm{ha}^{-1}$ menjadi 9.97 ton $\mathrm{ha}^{-1}$. Penurunan produktivitas mentimun salah satunya dapat disebabkan oleh benih dari varietas yang dibudidayakan. Meningkatnya produksi mentimun ini diperkirakan akan terus meningkat tiap tahunnya.
Petani di Indonesia banyak menanam varietas mentimun introduksi karena memiliki buah yang lebih besar dan seragam, akan tetapi benih ini tidak dapat ditanam kembali pada periode tanam berikutnya. Oleh karena itu perlu dilakukan upaya khusus untuk memperbaiki sifat genetik benih pada tanaman mentimun ini bisa ditempuh salah satunya dengan cara pemuliaan tanaman (Pardal, 2014).

Sinar gamma yang digunakan untuk radiasi adalah hasil peluruhan inti atom Cobalt-60. Cobalt-60 adalah sejenis metal yang mempunyai karateristik hampir sama dengan besi/nikel (Sinaga, 2000). Menurut Cobalt-60 ini memancarkan dua sinar gamma dengan energi masing- masing sebesar 1,17 MeV dan 1,13 MeV yang mempunyai waktu paruh 5,27 tahun (Utami, 2016).

Tujuan penelitian ini untuk mengetahui dan mendapatkan nilai $\mathrm{LD}_{50}$ serta pertumbuhan dari tanaman mentimun lokal Madura yang diiradiasi sinar Gamma Cobalt-60.

\section{METODE PENELITIAN}

\section{Rancangan Penelitian}

Penelitian akan dilaksanakan mulai bulan Mei sampai Juni 2021. Penyinaran sinar gamma ini dilaksanakan di 
Laboratorium Pusat Aplikasi Isotop dan Radiasi Badan Tenaga Nuklir Nasional (PAIR BATAN), Pasar Jumat, Jakarta. Percobaan dilakukan di Desa Burneh, Kecamatan Burneh, Kabupaten Bangkalan.

Penelitian ini menggunakan satu faktor perlakuan yaitu benih mentimun yang diradiasi sebanyak 10 perlakuan masing masing perlakuan terdapat 100 benih yang diradiasi, terdiri dari 11 taraf dengan kode $\mathrm{D}_{0}$ tanpa iradiasi (0Gy/ kontrol), $\mathrm{D}_{1}$ (100Gy), D 2 (200Gy), D 3 (300Gy), D (400Gy), D 5 (500Gy), D 6 (600Gy), $\mathrm{D}_{7}$ (700Gy), $\mathrm{D}_{8}$ (800Gy), $\mathrm{D}_{9}$ (900Gy), $\mathrm{D}_{10}$ (1000Gy). Terdapat 11 petak percobaan dan menggunakan single plant yang merupakan menaman tanpa adanya ulangan di lingkungan pertanaman yang sama. Tanaman untuk perkecambahan lethal dose terdiri dari 100 benih per dosis, kemudian di transplating pada setiap percobaan yang terdiri dari 40 tanaman per dosis. Pengamatannya dilakukan dengan mengamati seluruh sampel tanaman.

Pelaksanaan penelitian meliputi persiapan benih, Benih mentimun ini diirradiasi menggunakan mesin irradiator gammacell 220., persiapan media tanam yang dilakukan satu minggu sebelum penanaman dilakukan. Media tanam ini dibuat dengan mencampurkan tanah, pupuk kandang dan kompos dengan perbandingan 2:1:1, persemaian, transplating, penanaman dan perhitungan nilai lethal dose, dan pemeliharaan.

\section{Rancangan Percobaan}

Penelitian ini menggunakan satu faktor perlakuan yaitu benih mentimun yang diradiasi sebanyak 10 perlakuan masing - masing perlakuan terdapat 100 benih yang diradiasi, Dosis yang diberikan setiap perlakuan adalah 100 Gy sampai 1000 Gy, kemudian benih dikecambahkan sebanyak 100 benih selama 14 hari, setelah disemai benih diseleksi sebanyak 40 bibit yang terbaik dan di transplanting ke lahan sesuai denah percobaan.

Parameter pengamatan yang diamati dalam penelitian ini yaitu nilai lethal dose, tinggi tanaman, bobot buah dan panjang buah. Analisis data yang digunakan yaitu pengujian nilai lethal dose dengan aplikasi Curve expert 1.4 dan analisis Uji $\mathrm{T}$ dilakukan untuk membandingkan setiap perlakuan dosis iradiasi sinar gamma ${ }^{60} \mathrm{Co}(100 \mathrm{~Gy}-1.000$ Gy) dengan kontrol (0 Gy). Analisis Uji T dilakukan dengan membandingkan nilai $\mathrm{T}$ hitung dan $\mathrm{T}$ tabel dengan rumus menurut Kusumaningrum (2008) : 


$$
\begin{gathered}
\text { thitung }=\frac{|\bar{A}-\bar{B}|}{S_{(X-B)}} \\
S_{(A-B)}=\sqrt{\frac{S_{A}^{2}+S_{B}^{2}}{n}} \\
\text { dimana } \\
S_{A}^{2}=\frac{1}{n} \sum_{i=1}^{n}\left(A_{i}-\bar{A}\right)^{2} \text { dan } S_{B}^{2}=\frac{1}{n} \sum_{i=1}^{n}\left(B_{i}-\bar{B}\right)^{2}
\end{gathered}
$$

Keterangan :

$$
\begin{array}{ll}
\mathrm{A} & =\text { nilai rata-rata sampel A } \\
\mathrm{B} & =\text { nilai rata-rata sampel } \mathrm{B} \\
\mathrm{S}_{(\mathrm{A}+\mathrm{B})} & =\text { standar eror } \\
\mathrm{S}^{2}{ }_{\mathrm{A}} & =\text { nilai varian (ragam) } \mathrm{A} \\
\mathrm{S}^{2}{ }_{\mathrm{B}} & =\text { nilai varian (ragam) } \mathrm{B} \\
\mathrm{A}_{\mathrm{i}} & =\text { nilai sampel A ke } \mathrm{i} \\
\mathrm{B}_{\mathrm{i}} & =\text { nilai sampel } \mathrm{B} \text { ke } \mathrm{i} \\
\mathrm{n} & =\text { besarnya sampel }
\end{array}
$$

\section{Bahan dan Alat}

Bahan yang akan digunakan polybag, tray, bak plastik, benih mentimun lokal Madura yang diradiasi dengan sinar gamma Cobalt-60. Benih di radiasi di Badan Tenaga Nuklir (BATAN) di Jakarta, tanah, pupuk kandang, kompos, pupuk Urea, pupuk KCL dan pupuk ZA. Pestisida yang digunakan sesuai dengan serangan dan apabila dibutuhkan.

Alat yang akan digunakan dalam penelitian ini meliputi mesin irradiator gammacell 220, cangkul, gembor, penggaris, dan timbangan analitik.

\section{HASIL DAN PEMBAHASAN}

Persentase Perkecambahan

Banyaknya benih yang berkecambah dari total yang ditanam pada penelitian dapat menghasilkan presentase perkecambahan. Pada tabel 1 telah disajikan persentase perkecambahan mentimun lokal Madura dengan penyinaran sinar gamma Cobalt-60.

Tabel 1. Persentase perkecambahan mentimun lokal madura dengan penyinaran sinar gamma Cobalt-60.

\begin{tabular}{lcc}
\hline $\begin{array}{c}\text { Perlakuan } \\
\text { Dosis } \\
\text { Iradiasi }\end{array}$ & $\begin{array}{c}\text { Jumlah Benih } \\
\text { yang } \\
\text { Dikecambahkan }\end{array}$ & $\begin{array}{c}\text { Persentase } \\
\text { Perkecambahan }\end{array}$ \\
$\mathrm{D}_{0}(0$ & 40 & $100 \%$ \\
$\mathrm{~Gy} /$ kontrol $)$ & 40 & $89 \%$ \\
$\mathrm{D}_{1}(100 \mathrm{~Gy})$ & 40 & $85 \%$ \\
$\mathrm{D}_{2}(200 \mathrm{~Gy})$ & 40 & $79 \%$ \\
$\mathrm{D}_{3}(300 \mathrm{~Gy})$ & 40 & $79 \%$ \\
$\mathrm{D}_{4}(400 \mathrm{~Gy})$ & 40 & $77 \%$ \\
$\mathrm{D}_{5}(500 \mathrm{~Gy})$ & 40 & $73 \%$ \\
$\mathrm{D}_{6}(600 \mathrm{~Gy})$ & 40 & $51 \%$ \\
$\mathrm{D}_{7}(700 \mathrm{~Gy})$ & 40 & $33 \%$ \\
$\mathrm{D}_{8}(800 \mathrm{~Gy})$ & 40 & $25 \%$ \\
$\mathrm{D}_{9}(900 \mathrm{~Gy})$ & & \\
$\mathrm{D}_{10}(1000$ & 40 & $23 \%$ \\
$\mathrm{~Gy})$ & & \\
\hline
\end{tabular}

Tabel 1. ini menunjukkan bahwa hasil iradiasi sinar gamma Cobalt-60 pada dosis $\mathrm{D}_{0}-\mathrm{D}_{10}(0-1000 \mathrm{~Gy})$ memiliki persentase perkecambahan mentimun lokal Madura di masing-masing perlakuan yang tidak bisa tumbuh dengan baik. Pada tabel tersebut dapat diketahui bahwa semakin tinggi dosis yang dilakukan, maka semakin kecil persentase kecambah normalnya. Perlakuan dosis iradiasi dalam perlakuan ini dapat menyebabkan terganggunya pertumbuhan dan perkembangan tanaman mentimun. 
Berikut ini hasil persentase perkecambahan mentimun dengan sinar gamma Cobalt-60 yang dapat dilihat dengan kurva perkecambahan linear dengan menggunakan aplikasi Curve Expert 1.4 yang dilanjutkan dengan mencari hasil persamaan regresi sederhana dengan menganalisis kurva perkecambahan.

Dilihat dari data persentase perkecambahan pada tanaman mentimun ini menjelaskan bahwa pada setiap benih mengalami kerusakan, ada beberapa benih yang telah ter-iradiasi dengan dosis yang tinggi mengalami kematian dan kegagalan berkecambah dengan normal. Pada dosis 1000 Gy yang ada dalam data pengamatan terlihat memiliki persentase perkecambahan yang sangat rendah yaitu 23\%. Tinggi rendahnya perkecambahan pada tanaman mentimun di berbagai dosis. Hal tersebut menyebabkan perbedaan karakter pada tiap tanaman, sejalan dengan pendapat (Bete, Tanasib, dan Pasangka, 2020) bahwa sinar gamma dapat merubah sifat genetik dari suatu tanaman, hal ini disebabkan karena dengan adanya sinar dapat memutuskan kromosom pada suatu gen yan membawa sifat keturunan. Tentunya, sifat yang dihasilkan memiliki karakteristik yang berbeda dengan induknya.

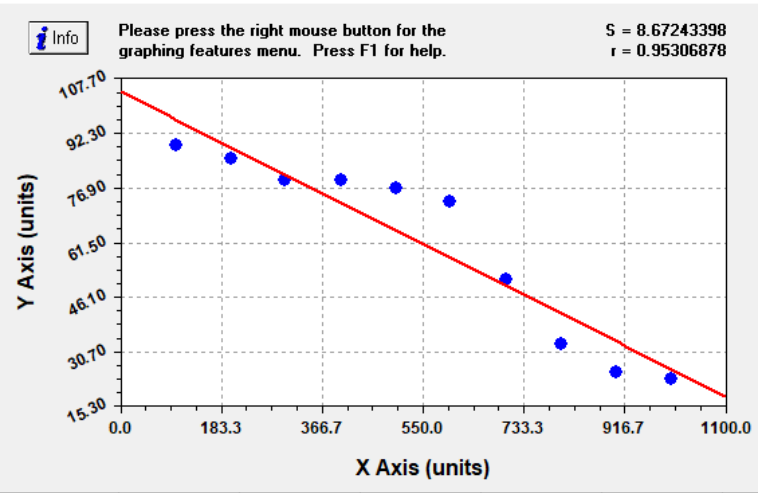

Gambar 1. Kurva respon perkecambahan tanaman mentimun hasil iradiasi sinar gamma Cobalt60

Arah kurva menurun ke kanan pada (Gambar 1.) yang dimulai dari tanaman kontrol sampai perlakuan dosis iradiasi terbesar. Hal tersebut disebabkan oleh pertumbuhan pada kecambah benih normal yang mengalami penurunan pada masingmasing perlakuan dosis.

Penggunaan program aplikasi Curve expert 1.4 ini bisa dilakukan juga dengan menggunakan persamaan regresi linier $\mathrm{y}=\mathrm{a}$ + bx untuk penentuan dosis sinar gamma yang menyebabkan LD 20 dan LD 50. Berdasarkan kurva respon tersebut didapatkan persamaan $\mathrm{y}=1,03+(-7,80 \mathrm{x})$. Dimana nilai y ini adalah persentase tanaman hidup, dan nilai $\mathrm{x}$ ini adalah dosis iradiasi yang menyebabkan kematian pada tanaman. Pada curve expert yang bernilai y ini diisi dengan 80 yang berarti 80\%tanaman hidup dengan $20 \%$ tanaman mati, makadi diketahui nilai $\mathrm{x}$ yang 
Perbal: Jurnal Pertanian Berkelanjutan

Fakultas Pertanian Universitas Cokroaminoto Palopo

merupakan nilai LD 20 yang menjadi penyebab tanaman mati sebanyak $20 \%$ yatu 306,752 Gy, kemudian pada saat nilai y diisi dengan 50 yang erarti $50 \%$ tanaman dengan $50 \%$ tanaman mati, dapat diketahu nilai x yang merupakan nilai LD 50 yang menjadi penyebab tanaman mati sebanyak $50 \%$ yaitu sebesar 690,92 Gy.

\section{Tinggi Tanaman}

Tabel 2. Hasil rata - rata tinggi tanaman mentimun lokal madura

\begin{tabular}{rrrrr}
\hline \multirow{2}{*}{ Perlakuan } & \multicolumn{5}{c}{ Tinggi Tanaman $(\mathrm{cm})$ Hst } \\
\cline { 2 - 5 } & 7 & 14 & 21 & 28 \\
\hline D0 (0 & & & & \\
Gy/Kontrol) & 6,09 & 12,77 & 38,22 & 71,83 \\
D1 (100 Gy) & $7,18^{* *}$ & $14,06 * *$ & $43,44 * *$ & $79,39 * *$ \\
D2 (200 Gy) & $6,63 * *$ & $14,00^{*}$ & $36,20 * *$ & 69,25 \\
D3 (300 Gy) & $6,97 * *$ & $14,12 * *$ & $36,16^{* *}$ & $59,86^{*}$ \\
D4 (400 Gy) & $7,08^{* *}$ & 12,85 & $35,69 * *$ & $58,50 * *$ \\
D5 (500 Gy) & $7,18^{* *}$ & 13,51 & $32,12^{* *}$ & $42,79 * *$ \\
D6 (600 Gy) & $7,01 * *$ & $12,63 *$ & $27,24 * *$ & $45,66^{* *}$ \\
\hline
\end{tabular}

\begin{tabular}{rrrr}
\hline \multirow{2}{*}{ Perlakuan } & \multicolumn{3}{c}{ Tinggi Tanaman $(\mathrm{cm})$ Hst } \\
\cline { 2 - 4 } & 35 & 42 & 49 \\
\hline D0 (0 & 88,76 & 108,76 & 206,68 \\
Gy/Kontrol) & & & \\
D1 (100 Gy) & $84,14 * *$ & $150,50 * *$ & 222,20 \\
D2 (200 Gy) & $105,26 *$ & $121,60 * *$ & 222,77 \\
D3 (300 Gy) & $102,90 * *$ & $107,59 * *$ & 196,79 \\
D4 (400 Gy) & $97,31 * *$ & $107,74 * *$ & 200,03 \\
D5 (500 Gy) & $84,28 * *$ & $89,57 * *$ & 181,20 \\
D6 (600 Gy) & $82,65 * *$ & $122,96 * *$ & 176,41 \\
\hline
\end{tabular}

\footnotetext{
Keterangan : * berbeda nyata terhadap D0 (0 Gy/control) berdasarkan uji t pada taraf 5\%,

**berbeda sangat nyata terhadap D0 (0 Gy/kontrol) berdasarkan uji t pada taraf $1 \%$
}

Tabel parameter tinggi tanaman terlihat perlakuan dosis 100 Gy - 600 Gy berbeda sangat nyata dengan perlakuan kontrol dalam parameter tinggi tanaman hampir di seluruh pengamatan HST yaitu sampai pada 42 HST. Adapun yang menunjukkan hasil berbeda nyata dengan tanaman kontrol pada 14 HST pada dosis 200 Gy dan 600 Gy, adapun juga berbeda nyata pada tanaman 28 HST di dosis 300Gy dan pada 35 hst di dosis 200 Gy. Pada 49 HST, terlihat pada data bahwa tidak berbeda nyata antara kontrol hingga dosis $600 \mathrm{~Gy}$.

Parameter tinggi tanaman ini yang bisa diamati pada tabel 2 memiliki nilai rata-rata yang menurun dari dosis perlakuan 100 Gy - 600 Gy. Hal ini sejalan dengan beberapa penelitian menurut Sutapa dan Antha (2016) bahwa dengan adanya pemberian sinar gamma ini dapat menurunkan presentase pertumbuhan tanaman akibat adanya efek deterministik yang muncul karena dosis paparan radiasi yang diberikan, sehingga semakin tinggi dosis iradiasi, maka kerusakan yang dialami oleh tanaman semakin besar.

\section{Bobot Buah dan Panjang Buah}

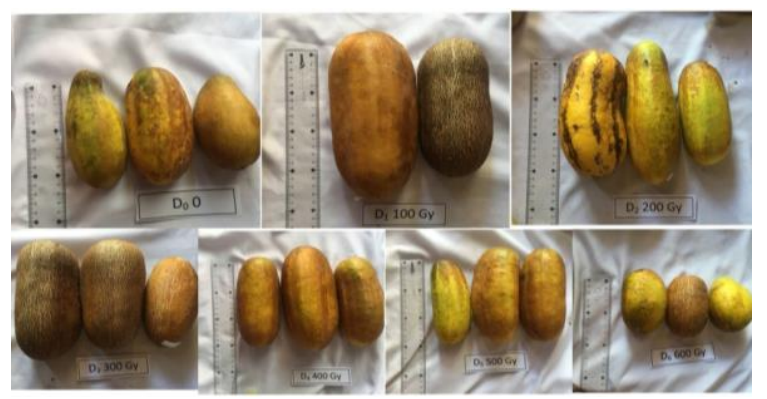

Gambar 2. Hasil pengukuran panjang buah 
Pengukuran pada parameter panjang buah mentimun lokal Madura menggunakan alat ukur penggaris. Terlihat pada (Gambar 2) dosis 100 Gy memiliki ukuran yang lebih panjang dibandingkan dengan kontrol dan dosis yang lain. Sedangkan pada dosis 600 Gy memiliki ukuran yang lebih pendek dibandingkan dengan kontrol dan dosis yang lainnya.

Tabel 3. Rata - rata bobot buah dan panjang buah mentimun lokal madura hasil radiasi sinar gamma Cobalt-60

\begin{tabular}{|c|c|c|}
\hline $\begin{array}{c}\text { Dosis Iradiasi } \\
\text { Sinar } \\
\text { Gamma Cobalt- } \\
60\end{array}$ & Bobot Buah & $\begin{array}{c}\text { Panjang } \\
\text { Buah }\end{array}$ \\
\hline $\begin{array}{r}\mathrm{D} 0(0 \\
\text { Gy/Kontrol })\end{array}$ & 17,06 & 11,69 \\
\hline D1 (100 Gy) & 22,16 & $17,92 *$ \\
\hline D2 (200 Gy) & 15,44 & 12,53 \\
\hline D3 (300 Gy) & 18,40 & 17,92 \\
\hline D4 (400 Gy) & 17,86 & 17,84 \\
\hline D5 (500 Gy) & 14,08 & 15,61 \\
\hline D6 (600 Gy) & 15,00 & 7,76 \\
\hline
\end{tabular}

(Tabel 3) memperlihatkan bobot buah mentimun yang dihasilkan untuk setiap masingmasing tanaman yang telah dilakukan radiasi. Tampak dengan jelas tidak ada perbedaan pada bobot buah yang telah dipapar iradiasi sinar gamma antara kontrol dan dosis yang lainnya. Hasil rata - rata uji $\mathrm{T}$ pada pemgamatan ini tidak adanya pengaruh. Sedangkan pada parameter panjang buah, hasil rata-rata teringgi pada dosis 100 Gy yang berbeda nyata terhadap control dan dosis yang lainnya. Perlakuan pada setiap kenaikan dosis iradiasi terjadi perubahan yang dapat menimbulkan keragaman dan terlihat acak. Bersifat random atau tidak bisa diprediksi yang mengakibatkan hal tersebut bisa terjadi. Kondisi tidak adanya perbedaan pada variabel variabel panjang buah dan bobot buah diduga karena pengamatan ini masih berlangsung pada tanaman hasil radiasi generasi pertama atau dapat dikatakan M0, sehingga pada variabel produksi belum terlihat pengaruhnya. Sejalan dengan pendapat Ali et al. (2016) perubahan karakter pada tanaman untuk memperoleh keragaman genetik terutama untuk meningkatkan produktivitas umumnya akan terjadi pada generasi lanjutan.

\section{KESIMPULAN DAN SARAN}

Hasil penelitian menunjukan dosis iradiasi sinar gamma Cobalt-60 mendapatkan nilai Lethal Dose 20 (LD20) sebesar 306,752 Gy dan Lethal Dose 50 (LD50) sebesar 690,92 Gy. Iradiasi sinar gamma Cobalt-60 berpengaruh terhadap pertumbuhan dan hasil produksi pada parameter tinggi tanaman, bobot buah dan panjang buah pada mentimun lokal Madura. Perlakuan 300 Gy mendapatkan mutan yang memiliki tinggi tanaman yang lebih unggul daripada dosis yang lainnya, dan juga perlakuan 100 Gy mendapatkan bobot buah yang lebih besar dari dosis lain dan juga pada parameter panjang buah yang memiliki 
Perbal: Jurnal Pertanian Berkelanjutan

Fakultas Pertanian Universitas Cokroaminoto Palopo

ukuran yang lebih unggul. Dosis 700 Gy 100 Gy mendapatkan tanaman lethal pada saat pertumbuhan. Dengan adanya penelitian pada tahapan awal ini, diharapkkan bisa dilakukan pada generasi selanjutnya dari awal sampai proses pemanenan agar diperoleh varietas unggul baru,

\section{DAFTAR PUSTAKA}

Ali, H., Ghori, Z., Sheikh, S. \& Gul, A. (2016). Effects of Gamma Radiation on Crop Production. Crop Production and Global Enviromental Issues. Springer International Publishing Switzerland. K.R. Hakeem (ed.), DOI 10.1007/9783-319-23162-4_2.

Badan Pusat Statistik. (2015). Statistika Produksi Hortikutura Tahun 2014. Kementerian Pertanian Direktorat Jenderal Hortikultura. http://hortikultura.pertanian.go.id. 15 Maret 2021.

Bete, A., Tanesib, J., dan Pasangka, B. (2020). Pemuliaan Tanaman Kacang Tunggak (Vigna unguiculata) Lokal Malaka Dengan Metode Irradiasi Multigamma. Jurnal Fisika Volume 5, Nomor 2.

Indriani, F. C., Sudjindro, Arifin. N. S., dan Lita S. (2008). Keragaman Genetik Plasma Nutfah Kenaf (Hibisus cannabinus L.) dan Beberapa Species yang Sekerabat Berdasarkan Analisis Isozim . Dikutip darihttp://images.soemarno.multiply.co m/attachment/0/Rfux4goKCpkAABt7L qs1/rami4.doc?nmid=223323374. 27 November 2021.

Kusumaningrum. (2008). Dasar Perancangan Percobaan dan Rancangan Acak Lengkap. Surabaya: Airlangga University Press. 78 Halaman.
Pardal, S.J. (2014). Teknik Mutasi untuk Pemuliaan Tanaman. http://bbbiogen.litbang.pertanian.go.id . 28 Desember 2021.

Sinaga, R. (2000). Pemanfaatan Teknologi Iradiasi dalam Pengawetan Makanan. Prosiding 2 Seminar Ilmiah Nasional dalam Rangka Lustrum IV. Fakultas Biologi Universitas Gajah Mada. Yogyakarta: MEDIKA. 2-7 hal.

Sutapa, G.N., dan I Gede Antha Kasmawan. (2016). Efek Induksi Mutasi Radiasi Gamma 60Co pada Pertumbuhan Fisiologis Tanaman Tomat (Lycopersicon esculentum L.). Jurnal Keselamatan Radiasi dan Lingkungan Volume 1. Nomor 2.

Utami, M.S. (2016). Aplikasi Teknologi Radiasi Gamma (Radiosotop CO-60 untuk Proses Pengawetan Buah. Semarang. 13-15 halaman. 